\title{
A preliminary study on the engineering properties of clay soil
}

Mehrin Hoque ${ }^{1}$, Akhila Palat ${ }^{1}$, Michael Hendry ${ }^{1}$

${ }^{1}$ Department Civil and Environmental, University of Alberta

\section{Abstract}

Karl Von Terzaghi, the father of soil mechanics, says, "There is no other soil which is as problematic as clay soil". In many places across the badlands of Alberta, clay soil is known to be troublesome and cause issues with buildings and infrastructure. Climate conditions, erosion and weathering can cause the unstable clay soil to create landslides, which consequently damage many of these structures. For this reason, engineers are sent to these sites to monitor and collect data over a period of time to compare and contrast their results. The purpose of this study is to learn and understand the properties of clay soils through different classification and index tests. Two clay soils, kaolinite and bentonite, were tested for their properties and their results were compared. Some of the tests performed include the hydrometer analysis, pycnometer analysis, and atterberg limits. The hydrometer analysis is the process in determining the size of silts and clays (when sieves cannot be used). The pycnometer analysis is used to determine the specific gravity of a substance. Atterberg limits are used to determine the water content at which a soil starts to shift from liquid, plastic or semi-solid. These tests were done in two different solutions - one containing distilled water and one with saline water to understand the effect of the solution on the liquid and plastic limits. The goal of this study was achieved and the results can be used to understand more about the engineering properties of clay soils and apply these studies to future field work. By understanding these properties, further research can be done to discover long term solutions to landslides caused by the problematic soil.

Key words:

soil, clay, clay soil, central alberta, badlands, kaolinite, bentonite

Cite as: Hoque M., Palat A., and Hendry M. 2019. A preliminary study on the engineering properties of clay soil. Alberta Academic Review, Vol 2 (2) 39-40, WISEST Special Issue (not peer-reviewed), DOI 10.29173/aar47. 
Hoque et al., 2019

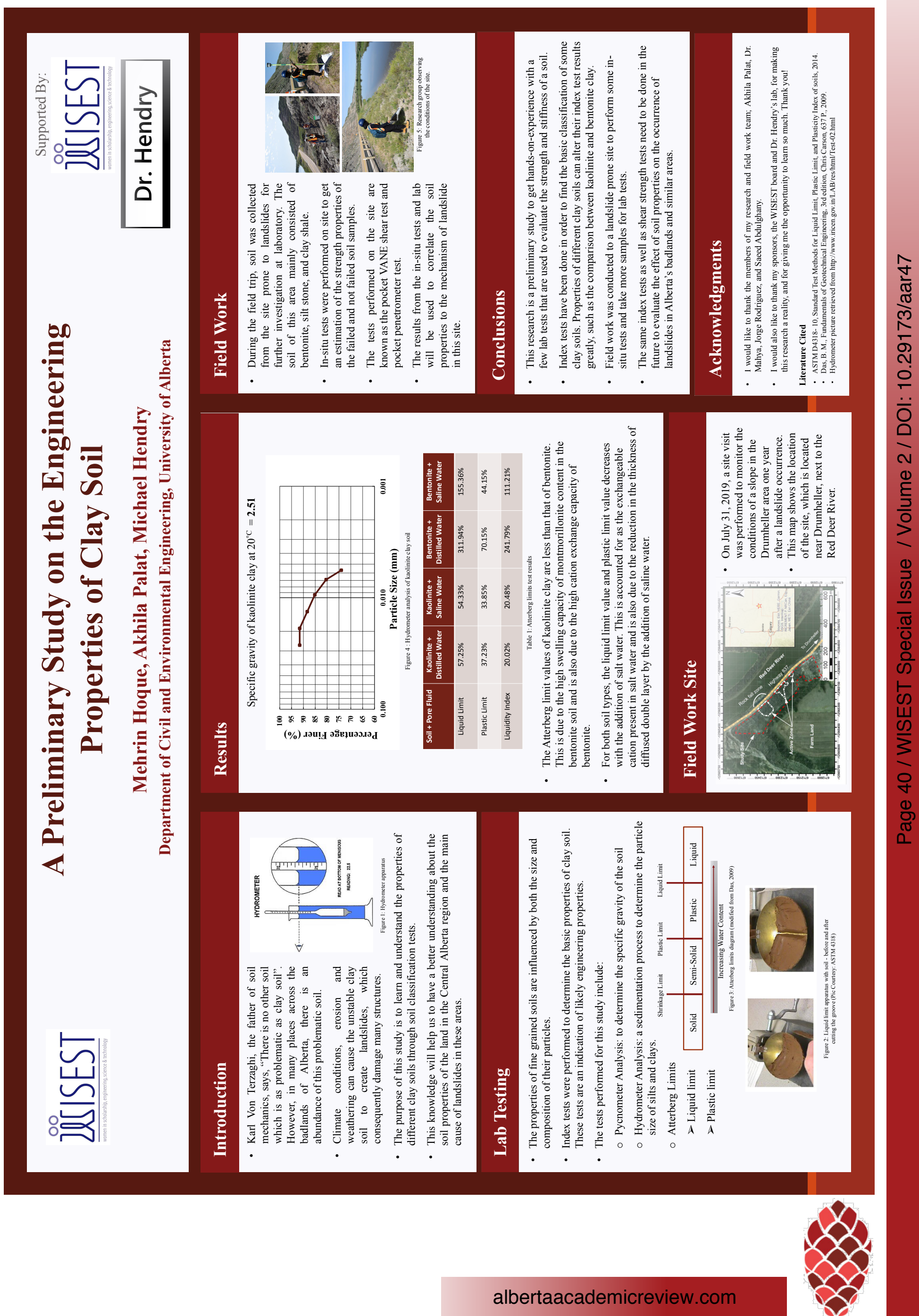

